\title{
EFEITO DA MONENSINA SÓDICA NO CONSUMO DE ALIMENTOS E pH RUMINAL EM OVINOS
}

\author{
(Effect of sodium monensin on food intake and ruminal $\mathrm{pH}$ in sheep)
}

\author{
ARAÚJO, J.S.'; PEREZ, J.R.O.'; PAIVA, P.C.A. ${ }^{2}$; PEIXOTO, E.C.T.M. ${ }^{3}$; \\ BRAGA, G.C. ${ }^{3}$; OLIVEIRA, V.; VALLE, L.C.D. ${ }^{4}$
}

\author{
'Docente da Universidade Estadual do Oeste do Paraná - UNIOESTE/CCA; \\ ${ }^{2}$ Docentes DZO/UFLA - Lavras-MG; \\ ${ }^{3}$ Docentes UNIOESTE/CCA - Mal. C. Rondon-PR; \\ ${ }^{4}$ Acadêmica do Curso de Zootecnia - UNIOESTE - Mal. C. Rondon-PR.
}

\begin{abstract}
RESUMO - Objetivou-se avaliar os efeitos da adição da monensina sódica no consumo de alimentos e no $\mathrm{pH}$ do líquido ruminal em ovinos. Foram utilizadas quatro ovelhas da raça Santa Inês, não prenhas, não lactantes e canuladas no rúmen. $O$ delineamento experimental utilizado foi o quadrado latino, com quatro tratamentos (T1 - 0; T2 - 25; T3 - 50 e T4 - 75 mg de monensina/ animal/dia). Foram avaliados o consumo de ração, de matéria seca e o $\mathrm{pH}$ do fluido do rúmen. A colheita do líquido ruminal para determinação do $\mathrm{pH}$ foi realizada às $0 ; 2 ; 4 ; 6$ e 8 horas após a alimentação. As análises de variância para consumo de ração e de matéria seca mostraram não haver efeito significativo dos níveis de monensina. Não foi observado efeito significativo nos valores médios do $\mathrm{pH}$ ruminal de cada tratamento e na interação tratamento x tempo; os valores de $\mathrm{pH}$ ruminal foram considerados normais. Houve diferença estatística no decorrer das horas. O consumo voluntário de alimentos e o $\mathrm{pH}$ do líquido ruminal não foram influenciados pela adição da monensina sódica na dieta dos ovinos, para a qual os valores de $\mathrm{pH}$ permaneceram elevados, caracterizando um bom ambiente de fermentação ruminal.
\end{abstract}

Palavras-Chave: Cordeiro, ionóforos, rúmen.

\begin{abstract}
The main aim of the present research work was the study of the effects of the ionophore sodium monensin on feed voluntary intake and on the $\mathrm{pH}$ of the ruminal liquid in sheep. Four Santa Inês non pregnant, non lactating and rumen-cannulated lambs were used within a Latin square experimental design with four treatments: T1 - 0; T2 - 25; T3 - 50 and T4 - 75 $\mathrm{mg}$ monensin/animal/day. Feed, dry matter intake and ruminal fluid $\mathrm{pH}$ were evaluated. Sampling of ruminal fluid for $\mathrm{pH}$ determination was carried out at 0, 2, 4, 6 and 8 hours after feeding. According to the analysis of variance no significant values were found for intake of diet and dry matter, in regard to the levels of monensin. No siginificant effect in the average values of ruminal $\mathrm{pH}$ of each treatment and in the treatment $\mathrm{x}$ time interaction were found, the $\mathrm{pH}$ values being considered normal. There was a statistic difference in regard to the
\end{abstract}

values found along the day. The voluntary feed intake and ruminal $\mathrm{pH}$ had not been influenced by the addition of sodium monensin in the diet of the sheep, the $\mathrm{pH}$ values remaining elevated, characterizing a good evironment of ruminal fermentation.

Key-words: Lamb, ionophores, rumen.

\section{Introdução}

As dietas para animais de alta produção são balanceadas com o objetivo de maximizar a ingestão de energia e a síntese microbiana, o que exige, em tese, alimentos altamente fermentáveis como fontes de energia para os microorganismos do rúmen. Para maximizar a produção ovina, além de uma densidade adequada de energia, os animais exigem também uma quantidade mínima de fibra para garantir a ruminação, a produção de saliva adequada, digestão satisfatória da fibra e manutenção do pH ruminal.

Para manter o $\mathrm{pH}$ ruminal próximo à neutralidade tem-se tentado manipular a dieta. Além da manipulação da dieta e da concentração dos nutrientes, vários aditivos vêm sendo utilizados na alimentação animal, entre eles os ionóforos como a monensina sódica. Esse tipo de ionóforo ajuda a restaurar o $\mathrm{pH}$ ruminal, já que inibe o crescimento de Streptococcus bovis, principal bactéria causadora da acidose láctica ruminal, podendo, gerar distúrbios metabólicos graves nos ruminantes (CHOW e RUSSELL, 1990). A monensina tem causado redução no consumo de alimento sem afetar negativamente o desempenho dos animais e de modificação da relação acetato: propionato, promovendo o aumento da eficiência ruminal, causado pela depressão da produção de ácido láctico sob condições que induzem a acidose, bem como redução da viscosidade do fluido ruminal em animais com timpanismo e melhorando o desempenho em função da estabilização do ambiente ruminal e proteção do trato gastrintestinal dos agentes patogênicos.

Sendo assim, o presente estudo teve como objetivo avaliar o consumo de nutrientes e o $\mathrm{pH}$ do líquido ruminal de ovinos alimentados com diferentes teores de monensina sódica. 
ARAÚJO, J.S. et al.

\section{Material e Métodos}

Foram utilizados quatro ovinos, adultos, fêmeas da raça Santa Inês com peso corporal médio de $35,13 \pm 0,79 \mathrm{~kg}$, canuladas no rúmen. Os animais foram mantidos em baias individuais de $5 \mathrm{~m}^{2} \mathrm{com}$ disponibilidade de bebedouro e comedouro. Os animais receberam uma dieta à base de volumoso e concentrado na proporção de 70:30, fornecida ad libitum, para atender às exigências nutricionais de ovelhas em mantença, segundo recomendações do NRC (1985). Foi fornecido um suplemento mineral comercial em cocho separado e água limpa à vontade. A composição percentual e química da dieta encontra-se na TABELA 1.

TABELA 1 - COMPOSIÇÃO PERCENTUAL E QUÍMICA DA DIETA (BASE DA MATÉRIA SECA).

\begin{tabular}{|c|c|}
\hline INGREDIENTES & $\%$ \\
\hline Farelo de soja & 20,00 \\
\hline Milho, grão moído & 9,50 \\
\hline Feno de Tifton 85 & 70,00 \\
\hline Suplemento mineral ${ }^{1}$ & 0,50 \\
\hline TOTAL & 100,00 \\
\hline NUTRIENTES & $\%$ \\
\hline Matéria Seca & 88,78 \\
\hline Proteína Bruta & 12,57 \\
\hline FDN - fibra em detergente neutro & 59,21 \\
\hline FDA - fibra em detergente ácido & 33,67 \\
\hline Matéria Mineral & 5,65 \\
\hline
\end{tabular}

'Suplemento Mineral Comercial - Cada 1000 g contém: P 87 g; Ca 120 g; Na 147 g; Mn 1300 mg; S 18 g; Zn 3800 mg; Mo 300 mg; Cu 590 mg; Fe 1800 mg; I 80 mg; Co 40 mg; Cr 20 mg; Se 15 mg; F (máx) 870 mg.

A monensina sódica foi fornecida misturada ao concentrado (aproximadamente $100 \mathrm{~g}$ ) para certificação da garantia total do consumo do ionóforo, e depois foi fornecida à ração diariamente, duas vezes ao dia. A sobra do alimento ofertado foi coletada diariamente, pesada e amostrada. As amostras foram congeladas, formando uma amostra composta do período por animal para posterior análise de matéria seca (MS) em estufa de 65 a $105^{\circ} \mathrm{C}$.

Foi utilizado o delineamento experimental em Quadrado Latino $4 \times 4$, (quatro tratamentos - T e quatro animais). Os tratamentos consistiram de níveis de monensina sódica, sendo: T1 - 0,0 mg/monensina sódica/animal/dia (controle); T2 - 0,25 mg/monensina sódica/animal/dia; T3 - 0,50 mg/monensina sódica/ animal/dia, e T4 - 0,75 mg/monensina sódica/animal/ dia. Os dados obtidos foram avaliados pelo procedimento GLM (Generalized linear models) do programa estatístico SAS (1991).

$\mathrm{O} \mathrm{pH}$ do líquido ruminal foi analisado estatisticamente como parcelas subdivididas no tempo. Os efeitos de tratamento, animal e período foram testados com relação às parcelas. A interação horários de coleta $x$ tratamentos foi testada com relação às subparcelas. O período experimental teve duração de 60 dias, subdividido em quatro sub-períodos de 15 dias cada. Ao longo dos 14 primeiros dias os animais foram submetidos à adaptação ao manejo e aos tratamentos, e no $15^{\circ}$ dia foi realizada a coleta de amostra de fluido ruminal para determinação do $\mathrm{pH}$. Após cada coleta, os animais foram submetidos ao rodízio nos tratamentos, conforme estabelecido pelo delineamento experimental utilizado. A coleta de líquido ruminal foi realizada sempre no $15^{\circ}$ dia de cada período e teve duração de um dia. As amostras de fluidos ruminais foram colhidas em diferentes tempos $(0,2,4$, 6 e 8 horas) após o fornecimento da ração. A coleta no tempo zero foi realizada antes do fornecimento da ração aos animais. As amostras de conteúdo ruminal foram filtradas em quatro camadas de tecido de algodão para se obter aproximadamente $50 \mathrm{~mL}$ de filtrado, que foi transferido para um recipiente para a determinação imediata do $\mathrm{pH}$, em potenciômetro digital $\mathrm{pH}$ Master, calibrado previamente com soluções tampão de $\mathrm{pH} 4,0$ e $\mathrm{pH} 7,0$.

\section{Resultados e Discussão}

$\mathrm{Na}$ TABELA 2 encontram-se os valores de $\mathrm{pH}$ em função dos tratamentos experimentais e nos diferentes tempos (horário). 
Efeito da monensina sódica no consumo de alimentos e pH ruminal em ovinos

TABELA 2 - EFEITOS DOS TEORES DE MONENSINA SÓDICA SOBRE O pH RUMINAL.

\begin{tabular}{cccccc}
\hline Tempos $^{1}$ & \multicolumn{3}{c}{ Tratamentos (mg de monensina/animal/dia) Subparcelas $^{2}$} \\
\cline { 2 - 4 } & 0 & 25 & 50 & 75 & \\
\hline 0 & 6,59 & 6,58 & 6,56 & 6,59 & $6,58^{\mathrm{bc}}$ \\
2 & 6,60 & 6,62 & 6,61 & 6,59 & $6,60^{\mathrm{c}}$ \\
4 & 6,59 & 6,57 & 6,56 & 6,58 & $6,57^{\mathrm{b}}$ \\
6 & 6,53 & 6,53 & 6,53 & 6,56 & $6,53^{\mathrm{a}}$ \\
8 & 6,56 & 6,49 & 6,54 & 6,55 & $6,53^{\mathrm{a}}$ \\
\hline Parcelas $^{3}$ & $6,57^{\text {ns }}$ & $6,55^{\text {ns }}$ & $6,56^{\text {ns }}$ & $6,57^{\text {ns }}$ & \\
\hline
\end{tabular}

1 - Horas após o fornecimento da ração pela manhã;

2 - Média das subparcelas (tempo);

3 - Média das parcelas (tratamentos);

Médias seguidas de letras iguais, na mesma coluna, não diferem entre si ( $\operatorname{Pr}>F)$.

ns = não significativo.

Esses resultados demonstram que a monensina sódica não causou efeito significativo nos valores médios de $\mathrm{pH}$ ruminal de cada tratamento (parcelas) e na interação tratamento $x$ tempo. Provavelmente esses valores foram obtidos em função da dieta ser predominantemente volumosa $(70 \%)$ e neste caso a monensina tenha menor ação,. Há relato na literatura, esclarecendo que quando os animais recebem monensina há maior proporção de concentrado. Neste caso esse ionóforo causa decréscimo na produção de metano primariamente, devido à menor disponibilidade de $\mathrm{H}_{2}$ e formiato e à reduzida transferência de $\mathrm{H}_{2}$ entre os microrganismos, bem como depressão da produção de ácido láctico sob condições que induzem à acidose mantendo o pH em níveis considerados normais.

Embora não se tenha observado efeito dos tratamentos no $\mathrm{pH}$, houve contudo diferença estatística $(\mathrm{P}<0,05)$ no decorrer do dia (subparcelas), caracterizando a curva padrão de fermentação ruminal (FIGURA 1). Isto ocorre porque quando ruminantes são alimentados com forragem e/ou dietas volumosas, o $\mathrm{pH}$ ruminal permanece próximo da neutralidade, devido a que a fibra estimula a ruminação, havendo, por conseqüência, uma grande produção de saliva, agindo como substância tampão natural do fluído ruminal.

\section{FIGURA 1 - EFEITOS DA MONENSINA SOBRE A VARIAÇÃO DIURNA DO pH NO FLUIDO RUMINAL.}

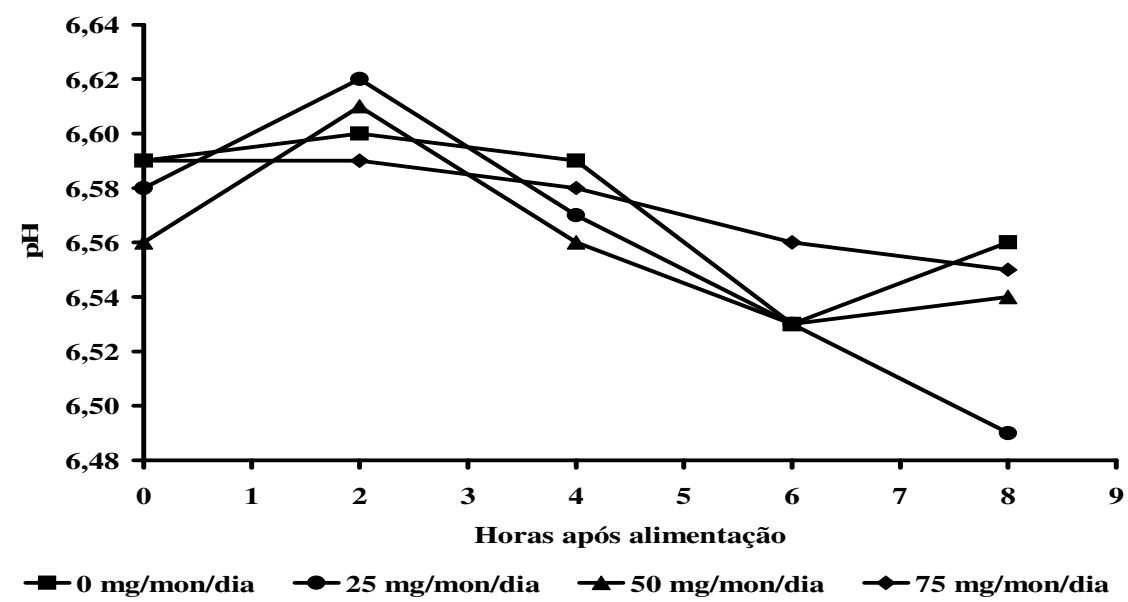

Esses resultados se assemelham àqueles apresentados por GARCIA et al. (2000), os quais não observaram mudança no $\mathrm{pH}$ ruminal ao fornecerem monensina a carneiros da raça Suffolk fistulados no rúmen. Do mesmo modo, MAAS et al. (2001), ao trabalharem com ovinos machos, castrados, canulados no rúmen e mantidos em pastagem recebendo ou não monensina sódica no suplemento mineral, também não observaram efeito significativo do ionóforo nos valores de $\mathrm{pH}$ ruminal.
OLIVEIRA et al. (2005 b) também não observaram alteração significativa de diferentes níveis do ionóforo monensina sódica incluído na dieta de novilhas leiteiras (67\% de volumoso) sobre o $\mathrm{pH}$ ruminal. Os resultados apresentados pelos autores supracitados foram superiores $(7,46)$ aos obtidos no presente experimento. Possivelmente, esses valores de $\mathrm{pH}$ inferiores a sete, indicam que não ocorreram contaminações do fluido ruminal com saliva, durante a coleta em função do método utilizado, ao passo que OLIVEIRA et al. (2005), 
efetuaram a coleta de líquido por sonda esofágica.

Já OLIVEIRA et al. (2005 a) ao trabalharem com novilhas holandesas fistuladas no rúmen alimentadas com dietas contendo teores baixo e alto de proteína com e sem monensina observaram efeito significativo com aumento do pH ruminal duas horas após alimentação ao adicionarem $28 \mathrm{mg}$ de monensina $/ \mathrm{kg}$ de matéria seca consumida em dietas com baixo $(11,45 \%)$ teor de proteína.

COE et al. (1999) descreveram que animais recebendo feno de alfafa apresentaram valores de $\mathrm{pH}$ ruminal semelhantes, independentemente do tipo e dos teores de ionóforos utilizados na dieta $(7,14 ; 7,14 ; 7,20$ e 7,16 para os tratamentos controle, $175 \mathrm{mg} / \mathrm{dia}$ de virginamicina, $250 \mathrm{mg} /$ dia de virginamicina e $250 \mathrm{mg}$ de monensina, respectivamente). Esses mesmos pesquisadores observaram que à medida em que se aumentava o nível de concentrado na dieta, ocorria uma diminuição no $\mathrm{pH}$ ruminal; no entanto, os valores de $\mathrm{pH}$ aumentavam quando eram adicionados ionóforos à dieta dos animais.

De acordo com OWENS e GOETSCH (1988), entre meia e quatro horas após a alimentação, o pH ruminal alcança os valores mais inferiores, refletindo o balanço entre a taxa de produção de ácidos, a entrada de tamponantes da saliva e a participação de tamponantes presentes no alimento. Ainda de acordo com esses autores, o pH varia entre 5,5 e 6,2 em uma dieta com maior teor de concentrado, enquanto que em dietas com maior participação de volumosos os valores situam-se entre 6,2 e 7,0.

A análise de variância para consumo de ração e de matéria seca mostrou não haver efeito significativo dos níveis de monensina sobre essas variáveis (TABELA3).

TABELA 3 - VALORES MÉDIOS DO CONSUMO MÉDIO DE RAÇÃO (CMR) E INGESTÃO DE MATÉRIA SECA (CMS) EM FUNÇÃO DOS NÍVEIS DE MONENSINA.

\begin{tabular}{lccccccc}
\hline & \multicolumn{4}{c}{ (mg de monensina/animal/dia) } & \multirow{2}{*}{ CV (\%) } & Média & \multirow{2}{*}{$\operatorname{Pr}<\mathrm{F}$} \\
\cline { 2 - 5 } \multicolumn{1}{c}{ Variáveis } & 0 & 25 & 50 & 75 & & & \\
\hline CMR (kg/dia) & 0,914 & 1,054 & 1,067 & 0,980 & 14,28 & 1,004 & 0,460 \\
CMS (kg/dia) & 1,029 & 1,202 & 1,179 & 1,094 & 14,59 & 1,126 & 0,265 \\
\hline
\end{tabular}

Esses resultados assemelham-se aos apresentados por GARCíA et al. (2000) que ao trabalharem com carneiros fistulados no rúmen, verificaram que o consumo de matéria seca não foi alterado com a adição de monensina na dieta. BRODERICK (2004), administrando monensina a vacas leiteiras pluríparas alimentadas com silagem de alfafa, também não observou efeito significativo sobre o consumo de matéria seca.

Entretanto, em estudos realizados com novilhas e vacas de corte mantidas em regime de confinamento (RESTLE et al., 2001), com carneiros alimentados com capim fresco colhido na primavera e no outono (MAAS et al., 2001) e com novilhos Aberdeen Angus alimentados com dietas contendo farelo de soja (LANA e FOX, 2001), observaram-se redução no consumo de matéria seca (CMS) quando eram adicionados ionóforos nas dietas dos animais. ERICKSON et al. (2004) ao utilizarem os ionóforos monensina e lasalocida sódica na dieta de bovinos leiteiros também verificaram reduções no consumo de matéria seca, sendo que os animais tratados com $1 \mathrm{mg}$ de monensina/ $\mathrm{kg}$ de peso vivo apresentaram menor consumo.

O ionóforo funciona como um inibidor de apetite devido ao seu gosto amargo; no entanto, na presente pesquisa, ao contrário da maioria dos trabalhos, o fornecimento da monensina foi efetuado antes de os cordeiros receberem as refeições, dessa forma, não associando o ionóforo ao alimento.

Os efeitos dos ionóforos nos ruminantes são diversos e variáveis devido às diferenças entre animais, condições corporais, dietas, estágios fisiológicos entre outros. Apesar disso, os ionóforos parecem ter efeitos positivos e consistentes no metabolismo ruminal e, como conseqüência, na eficiência produtiva animal.

\section{Conclusão}

O consumo voluntário de alimentos e o pH do líquido ruminal não foram influenciados pela adição da monensina sódica na dieta dos ovinos, até o nível observado, onde os valores de $\mathrm{pH}$ mantiveram-se dentro dos valores considerados normais, podendo implicar em um meio favorável ao estabelecimento e crescimento populacional dos microorganismos ruminais, e traduzindo-se em maior eficiência energética aos ruminantes.

\section{Referências}

BRODERICK, G.A. Effect of low level monensin supplementation on the production of dairy cows fed alfalfa silage. Journal of Dairy Science. v.87, n.2, p.359-368, 2004.

CHOW J.M.; RUSSELL, J.B. Effect of ionophores and $\mathrm{pH}$ on growth of Streptococcus bovis in batch and continuous culture. Applied and Environmental Microbiology. v. 56, n.6, p. 1588-1593, 1990.

COE, M.L.; NAGARAJA, T.G.; SUN, Y.D.; WALLACE, N.; TOWNE, E.G.; KEMP, K.E.; HUTCHESON, J.P. Effect of virginamycin on ruminal fermentation in cattle during adaptation to a high concentrate diet and during an induced acidosis. Journal of Animal Science, v.77, n.8, p.2259-2268, 1999. 
Efeito da monensina sódica no consumo de alimentos e pH ruminal em ovinos

ERICKSON, P.S.; DAVIS, M.L.; MURDOCK, C.S.; PASTIR, K.E.; MURPHY, M. R.; SCHWAB, C.G. MARDEN, J.I. Ionophore taste preferences of dairy heifers. Journal of Animal Science. v.82, n.11, p.3314-3320, p.2004.

GARCÍA, C.C.G.; MENDOZA, M.G.D.; GONZÁLEZ, M.S.; COBOS, P.M.; ORTEGA C.M.E.; RAMIREZ, L.R. Effect of a yeast culture (Saccharomyces cerevisiae) and monensin on ruminal fermentation and digestion in sheep. Animal Feed Science and Technology, v.83, n.2, p.165170,2000

LANA, R.P.; FOX, D.G. Interações entre monensina sódica, óleo de soja e fontes de nitrogênio no desempenho de novilhos aberdeen angus em confinamento. Revista Brasileira de Zootecnia, v.30, n.1, p.247-253, 2001.

MAAS, J.A.; WILSON, G.F.; MCCUTCHEON, S.N.; LYNCH, G.A.; BURNHAM, D.L.; FRANCE, J. The effect of season and monensin sodium on the digestive characteristics of autumn and spring pasture fed to sheep. Journal of Animal Science, v.79, n.4 p.1052-1058, 2001.

NATIONAL RESEARCH COUNCIL. Nutrients requirements of sheep. Washington: National Academy, 1985. 99p.
OLIVEIRA, M.V.M.; LANA, R.P.; JHAM, G.N.; PEREIRA, J.C.; PÉREZ, J.R.O.; VALADARES FILHO, S.C. Influência da monensina no consumo e na fermentação ruminal em bovinos recebendo dietas com teores baixo e alto de proteína. Revista Brasileira de Zootecnia. v.34, n.5, p.1783-1774, 2005 a.

OLIVEIRA, M.V.M.; LANA, R.P.; FREITAS, A.W.P.; EIFERT, E.C.; PEREIRA, J.C.; VALADARES FILHO, S.C.; PÉREZ, J.R.O. Parâmetros ruminais, sanguíneo e urinário e digestibilidade de nutrientes em novilhas leiteiras recebendo diferentes níveis de monensina. Revista Brasileira de Zootecnia. v.34, n.6, p.2143-2154, 2005 b.

OWENS, F.N.; GOESTSCH, A.L. Ruminal fermentation. In: $\mathrm{CHURCH}, \mathrm{D}$.C. The ruminant animal digestive physiology and nutrition. Englewood cliffs: $O$ \& Books Inc., 1988. p.146-171.

RESTLE, J.; Neumann, M.; Alves Filho, D.C.; Pascoal, L.L.; ROSA, J.R.P.; MENEZES, L.F.G.; PELLEGRINI, L.G. Terminação em Confinamento de Vacas e Novilhas sob Dietas com ou sem Monensina Sódica. Revista Brasileira de Zootecnia, v.30, n.6, p.1801-1812, 2001.

SAS Institute. SAS/STAT user's guide. Cary, 1991.

Recebido para publicação: $\quad$ 08/01/2006 Aprovado: 